\title{
Isolation of Plesiomonas shigelloides from nutrient broth with brilliant green: its use in screening stool samples from an African population
}

\author{
P NAIR, S E MILLERSHIP \\ From the Department of Bacteriology, Royal Postgraduate Medical School, London
}

SUMMARY The suitability and selectivity of nutrient broth with bile salts and varying concentrations of brilliant green as an enrichment medium was tested for the isolation of Plesiomonas shigelloides from faeces. The broth was most effective at a concentration of $0.001 \mathrm{~g} / \mathrm{l}$ brilliant green, using faeces deliberately contaminated with Plesiomonas. Two hundred and nineteen faecal samples from Nigeria were then examined for the presence of Plesiomonas and other bacterial pathogens. One yielded Plesiomonas following enrichment in bile salts brilliant green broth (BBG broth) whereas no samples were positive on direct plating.

In 1947 Ferguson and Henderson ${ }^{1}$ described an organism with the somatic antigen of Shigella sonnei, which was later placed in a new genus Plesiomonas of the family Vibrionaceae, having a single species shigelloides. ${ }^{23}$ It is present in soil and surface water ${ }^{45}$ and has been found in drinking water in association with an outbreak of diarrhoea (B Chattopadhyay, personal communication). Most isolates from man have been from faeces or the gastrointestinal tract, ${ }^{6}$ and reports from several parts of the world have implicated Plesiomonas as a cause of gastroenteritis. ${ }^{3-9}$

This organism may well be more common than the few published reports would suggest. Investigation of its role in human disease, however, has been hampered by the lack of suitable primary isolation and enrichment media. Previous studies ${ }^{151011}$ have shown that although it will grow well in pure culture on many media, recovery is poor when it is in mixed culture. We report our findings on the selectivity of nutrient broth combined with bile salts and varying concentrations of brilliant green as an enrichment medium, and the use of this to examine a series of stool samples from an African population.

\section{Material and methods}

Four strains of Plesiomonas shigelloids were used in laboratory tests; two were supplied by Dr AL Furniss of Maidstone Public Health Laboratory comprising one agglutinating with $S$ sonnei antiserum (a) and one

Accepted for publication 29 January 1987

non-agglutinating (b). The remaining strains (c and d) were isolated from patients with diarrhoea; neither had $S$ sonnei phase I antigen.

Bile salts brilliant green agar (BBG) was prepared as previously described. ${ }^{11}$ Horse blood agar was supplied by Gibco. MacConkey agar (Oxoid) was made up according to the manufacturer's instructions. Four broths were tested: nutrient broth (Oxoid No 2) alone, and three nutrient broths with bile salts (Oxoid $\mathrm{L} 55,5 \mathrm{~g} / \mathrm{l})$ and $0.0005 \mathrm{~g} / 1,0.001 \mathrm{~g} / 1$, or $0.005 \mathrm{~g} / 1$ brilliant green, respectively. In all cases the broth was dispensed in $10 \mathrm{ml}$ aliquots and autoclaved at $15 \mathrm{lb}$ for 15 minutes. The final $\mathrm{pH}$ was $7 \cdot 17$ to $7 \cdot 2$ at $21^{\circ} \mathrm{C}$.

All test organisms were grown overnight at $37^{\circ} \mathrm{C}$ in nutrient broth and 10-fold dilutions made for a Miles $\delta$ and Mistra plate count ${ }^{12}$ on blood agar. Test stool specimens were pools of two to five random faecal $ᄋ$ specimens diluted 1:10 and emulisified in Ringer's solution. These were counted as above on MacConkey agar.

To evaluate the growth of small inocula in the test $N$ broths $0.02 \mathrm{ml}$ drops of 10 -fold dilutions of test $N$ organism were added to three $1 \mathrm{ml}$ aliquots of the rel- N evant broth and incubated at $37^{\circ} \mathrm{C}$ for 18 hours. $O$ Tubes showing growth were subcultured to check for purity. A medium was considered to be satisfactory if $\stackrel{0}{\circ}$ growth occurred in at least two of the three tubes to $\stackrel{\S}{\rightleftharpoons}$ which 1-10 colony forming units $/ \mathrm{ml}$ had been added.

Selectivity was examined by inoculating $0.02 \mathrm{ml}$ of 10 -fold dilutions of each test strain into $1 \mathrm{ml}$ aliquots $\mathbb{\mathbb { D }}$ of faecal suspension, mixing well, and plating out $\stackrel{\oplus}{\Phi}$ $0.001 \mathrm{ml}$ on BBG agar before adding $10 \mathrm{ml}$ of test $\frac{2}{\sigma}$ broth. All broths were incubated overnight at $37^{\circ} \mathrm{C}$. A 
sample of $0.001 \mathrm{ml}$ was then streaked out on BBG agar. Plates were incubated overnight at $37^{\circ} \mathrm{C}$, flooded with Kovac's oxidase reagent ${ }^{13}$ and positive colonies subcultured immediately on to blood agar. Identification was confirmed using API 20E trays according to the manufacturer's instructions. Uninoculated control samples of each faecal pool were also treated in the same way. One experiment was continued for 48 hours and another for 72 hours.

Two hundred and nineteen stool samples were collected from a Nigerian population. Specimens were frozen at $-70^{\circ} \mathrm{C}$ and thawed on the day of culture. They were plated out on BBG agar and about $1 \mathrm{~g}$ faeces added to each of $100 \mathrm{ml}$ of BBG broth with $0.001 \mathrm{~g} / 1$ brilliant green and alkaline peptone water. On the second day BBG broth and alkaline peptone water were subcultured to BBG agar. All media were incubated overnight at $37^{\circ} \mathrm{C}$, except alkaline peptone water, which was incubated at room temperature.

Oxidase positive colonies were identified as described previously. All stool specimens were also examined from Salmonella, Shigella, and Campylobacter spp using standard methods.

\section{Results}

All four test strains of Plesiomonas grew in nutrient broth and the three bile salts brilliant green (BBG) broths from an inoculum of 1-10 colony forming units $/ \mathrm{ml}$. Table 1 shows the results of artificially contaminated faeces in BBG broth compared with those obtained with direct plating. All faecal coliform counts were in the range $10^{6}-2.5 \times 10^{8}$. Nutrient broth and BBG with $0.0005 \mathrm{~g} / \mathrm{l}$ were abandoned after one experiment as no isolations of any of the test strains could be made even at concentrations of 10 Plesiomonas to one of faecal flora. In one experiment a stool specimen had a heavy growth of $P s$ aeruginosa. Plesiomonas could not be recovered either on direct plating or on enrichment from any sample and the results were omitted from the analysis.

Both enrichment broths with brilliant green were significantly better than direct plating at Plesiomonas to coliform ratios of $1:>10^{4}\left(p<0.001, \chi^{2}=13 \cdot 19\right.$ and $15 \cdot 31$, respectively). There was no significant difference between the two broths $\left(\chi^{2}=0 \cdot 09,0.80>\right.$ $\mathrm{p}>0 \cdot 50$ ). Increasing the incubation time to 48 hours considerably reduced the positive isolations and, by 72 hours, 13 of 20 positive test results were all negative.

There was also variation in the recovery rates of different strains (table 2). Strain (d) was more readily isolated than strain (a) (direct plating $p=0.015$, $0.001 \mathrm{~g} / 1$ broth $\mathrm{p}=0.0008,0.005 \mathrm{~g} / \mathrm{l}$ broth $\mathrm{p}=$ 0.00004; Fisher's exact test). In no case was either broth significantly worse than direct plating; in par-

Table 1 Recovery from artificially contaminated stools

No of stools positive/No of tests ( \%) at test organism: normal flora $\log _{10}$ ratio of:

\begin{tabular}{|c|c|c|c|c|c|}
\hline & $0-<1$ & $1-<2$ & $2-<3$ & $3-<4$ & $>4$ \\
\hline $\begin{array}{l}\text { BBG agar } \\
\text { BBG broth }(0.001 \mathrm{~g} / \mathrm{l})^{*} \\
\text { BBG broth }(0.005 \mathrm{~g} / \mathrm{l})^{*}\end{array}$ & $\begin{array}{l}8 / 8(100) \\
3 / 8(38) \\
5 / 8(63)\end{array}$ & $\begin{array}{l}3 / 8(38) \\
3 / 8(38) \\
4 / 8(50)\end{array}$ & $\begin{array}{l}1 / 8(13) \\
2 / 8(25) \\
4 / 8(50)\end{array}$ & $\begin{array}{l}3 / 16(19) \\
1 / 12(8) \\
2 / 12(17)\end{array}$ & $\begin{array}{l}0 / 46(0) \\
7 / 27(26) \\
8 / 27(30)\end{array}$ \\
\hline
\end{tabular}

*Concentration of brilliant green.

Table 2 Comparison of isolation rates of different test strains

\begin{tabular}{|c|c|c|c|c|}
\hline Strain & Direct plating & $B B G$ broth $(0.001 \mathrm{~g} / \mathrm{l})^{*}$ & $B B G$ broth $(0.005 \mathrm{~g} / \mathrm{l})^{*}$ & Totals (\%) \\
\hline $\begin{array}{l}a \\
b \\
c \\
d\end{array}$ & $\begin{array}{l}3 / 22 \\
3 / 22 \\
2 / 22 \\
7 / 20\end{array}$ & $\begin{array}{l}0 / 16 \\
2 / 16 \\
5 / 16 \\
8 / 15\end{array}$ & $\begin{array}{r}1 / 16 \\
3 / 16 \\
9 / 16 \\
12 / 15\end{array}$ & $\begin{array}{c}4 / 54(7) \\
8 / 54(15) \\
16 / 54(30) \\
27 / 54(50)\end{array}$ \\
\hline
\end{tabular}

*Concentration of brilliant green.

Table 3 Isolation of enteric pathogens from 219 stool samples tested: comparison of different media used

\begin{tabular}{|c|c|c|c|c|c|c|c|}
\hline Organism & $\begin{array}{l}\text { BBG solid } \\
\text { medium }\end{array}$ & BBG broth & $\begin{array}{l}\text { Campylobacter } \\
\text { medium }\end{array}$ & $\begin{array}{l}\text { Alkaline peptone } \\
\text { water }\end{array}$ & Selenite $F$ & $D C A$ & MacConkey \\
\hline Plesiomonas shigelloides & - & 1 & - & - & - & - & - \\
\hline Yersinia enterocolitica & - & 1 & - & - & - & 1 & - \\
\hline Salmonella spp & - & - & - & - & 5 & 2 & 2 \\
\hline Shigella sonnei & - & - & - & - & - & - & 2 \\
\hline Campylobacter spp & - & - & 4 & - & - & - & 2 \\
\hline
\end{tabular}


ticular, the probability of obtaining the results for strain (a) in enrichment medium with $0.001 \mathrm{~g} / 1$ brilliant green was $0 \cdot 25$ (Fisher's exact test).

Table 3 shows the results of examining 219 specimens of faeces from Nigeria. There was one isolate of Plesiomonas shigelloides from BBG broth alone. There were nine strains of Pseudomonas spp isolated from BBG broth which gave a positive oxidase reaction; six of these were also isolated from alkaline peptone water.

\section{Discussion}

Several studies have shown that Plesiomonas grows on a variety of conventional enteric media-for example, MacConkey, Salmonella-Shigella, and deoxycholate citrate agars. ${ }^{1511}$ Schubert suggested that this was not entirely satisfactory for primary isolation from mixed culture ${ }^{14}$ and devised a new medium, inositol brilliant green bile salts agar (IBB agar). This, or a modification of it, seems to be the solid medium of choice. ${ }^{1115}$

No satisfactory enrichment medium, however, has been described. Alkaline peptone water was effective in one study but not in others. ${ }^{1115}$ Our results show that brilliant green at the correct concentration is, as suggested by Winton, ${ }^{16}$ a useful selective agent. Nutrient broth alone is not useful so the effect is not simply one of dilution, also bile salts alone do not make any difference as, in the presence of a very low concentration of brilliant green, the broth is still ineffective. All the broths have a $\mathrm{pH}$ that is nearly neutral, ruling this out as the selective mechanism.

The interference with isolation caused by other oxidase positive colonies, particularly Ps aeruginosa, has been noted with alkaline peptone water but usually does not affect more than a few specimens, ${ }^{11}$ and our findings confirm this. The pronounced differences between test strains of Plesiomonas may explain previous discrepant results with alkaline peptone water enrichment. ${ }^{1115}$ For screening purposes it would be wise to use two enrichment broths - for example, brilliant green and alkaline peptone water.

In most of the prospective studies, workers have either failed to isolate Plesiomonas, or isolated it only in small numbers from the faecal samples tested. ${ }^{101517}$ Unfortunately, it was impractical to use a better preservation technique for the faecal samples examined in this study, and the relatively low isolation rates of other pathogens suggest that this may have been a factor in the failure to recover more
Plesiomonas. Our finding of a single isolate therefore suggests that BBG broth is useful as an enrichment medium, although further confirmation is needed.

\section{References}

1 Ferguson WW, Henderson ND. Description of strain C27: a motile organism with the major antigen of Shigella sonnei phase 1. J Bacteriol 1947;54:179-81.

2 Bader RE. Uber die Herstellung eines agglutinierenden Serums gegen die Rundform von Shigella sonnei mit einem Stamm der Gattung Pseudomonas. Zeitschrift für Hygiene und Infektionskrankheiten 1954;140:450-6.

3 Habs H, Schubert RHW. Uber die biochemischen Merkmale und die taxonomische Stellung von Pseudomonas shigelloides (Bader). Zentralblatt für Bakteriologie Parasitenkunde Infektionskrankheiten und Hygiene originale 1962;186:316-32.

4 Tsukamoto T, Kinoshita Y, Shimada T, Sakazaki R. Two epidemics of diarrhoeal disease possibly caused by Plesiomonas shigelloides. J Hgy (Camb) 1978;80:275-80.

5 Aldova E, Rakovsky J, Chovancova A. The microbiological diagnostics of strains of Aeromonas shigelloides isolated in Cuba. $J$ Hyg Epidemiol Microbiol Immunol 1966;10:470-82.

6 Penn RG, Giger DK, Knoop FL, Preheim LC. Plesiomonas shigelloides overgrowth in the small intestine. J Clin Microbial 1982;15:869-72.

7 Cooper RG, Brown GW. Plesiomonas shigelliodes in South Australia. J Clin Pathol 1968;21:715-18.

8 Chatterjee BD, Neogy KN. Studies on Aeromonas and Plesiomonas species isolated from cases of choleraic diarrhoea. Indian J Med Res 1972;60:520-4.

9 Jandl G, Linke K. Bericht uber zwei Falle von akuter gastroenteritis durch Plesiomonas shigelloides. Zentralblatt für Bakteriologie Parasitenkunde Infektionskrankheiten und Hygiene originale 1976;236:136-40.

10 Geizer E, Kopecky K, Aldova E. Isolation of Aeromonas Shigelloides in a child. $\mathrm{J}$ Hyg Epidemiol Microbiol Immunol 1966;10:190-4.

11 Millership SE, Chattopadhyay B. Methods for the isolation of Aeromonas hydrophila and Plesiomonas shigelloides from faeces. J Hyg (Camb) 1984;92:145-52.

12 Stokes EJ, Ridgway GL. Clinical bacteriology. London: Edward Arnold, 1976:215.

13 Cowan ST, Steel KJ. Manual for the identification of medical bacteria. Cambridge: Cambridge University Press, 1979:170.

14 Schubert RW. Uber den Nachweis von Plesiomonas shigelloids Habs und Schubert, 1962, und ein Electivmedium, den Inositol-Brillantgrun-Gallsalz-Agar. Einst-Rodenhaldt Archiv 1977:4:97-103.

15 Von Graevenitz A, Bucher C. Evaluation of differential and selective media for isolation of Aeromonas and Plesiomonas spp. from human feces. J Clin Microbiol 1983;17:16-21.

16 Winton FW. Plesiomonas shigelloides: an unusual isolate from faeces. Journal of Pathology and Bacteriology 1968;95:562-7.

17 Paukova V, Fukalova A. Occurrence of Aeromonas hydrophila and Aeromonas shigelloides in feces. Zentralblatt für Bakteriologie Parasitenkunde Infektionskrankheiten und Hygiene originale 1968;206:212-6.

Requests for reprints to: Dr P Nair, Department of Bacteriology, Royal Postgraduate Medical School, Hammersmith Hospital, Ducane Road, London W126HS, England. 